\title{
The sky is not flat: how discriminatory is the access to international air services?
}

\author{
By RoBERTA PIERMARTINI AND LiNDA ROUSOVÁ
}

\section{Online Appendix}

\section{Propensity score matching}

We also tackle endogeneity using propensity score matching. The idea is to reproduce a randomized experiment with a treatment and a control group. In the context of our analysis, we define the treatment as the implementation of a liberal ASA and choose a treated observation to be a country pair with an ALI value above the median (i.e., above 10). Therefore, the treatment group consists of all country pairs with an ALI above the median, whereas the control group consists of country pairs with restrictive ASAs (i.e., characterized by an ALI below 10). To approximate random allocation between the two groups, we select from our sample only those observations that are similar in terms of their other observed characteristics (except for passenger flows, our outcome of interest). The underlying idea is that if the treatment and control groups differed only in the treatment variable, the treatment would be truly randomized and the endogeneity problem would disappear. In particular, the propensity that an observation is treated, conditional on other observed characteristics, should be the same in the control and treated groups.

To match the treatment group to the control group, we use the probability that a certain country pair has a liberal ASA in place. We first calculate this probability by running a probit model for the existence of a liberal ASA. ${ }^{1}$

\footnotetext{
${ }^{1}$ As explanatory variables, we use all control variables in our benchmark model (that of Table 5, column (4)).
} 
Then, taking the predicted probabilities from this probit estimation (i.e., the propensity scores), we match observations from the treated group to those in the control group by applying the radius matching methodology. The advantage of adopting this matching technique compared with nearest neighbor matching or kernel matching is that it allows only for matches within a pre-specified propensity score distance (caliper) and thus minimizes the possibility of bad matches. ${ }^{2}$ Table F.1 illustrates that differences in the means of most variables (and in particular of the product of GDPs and face-to-face trade) across the control and treatment groups decrease because using the propensity score matching approach and similarly so do the standard deviations. Finally, using only the matched observations, we estimate the effect of the implementation of a liberal ASA on passenger traffic volumes and report the results in Table F.2, columns (3) and (4). We find a positive and significant effect of signing ambitious ASAs on passenger flows.

Interestingly, if we compare the results from the propensity score matching with those from the OLS estimations (columns 1 and 2), we find a higher and more significant effect of signing a deep ASA in the propensity score matching estimations. This is in line with the results we obtain by running IV estimations. Hence, both the propensity score matching and the IV technique suggest that OLS estimations suffer from downwards bias due to endogeneity.

\footnotetext{
${ }^{2}$ With radius matching, each treated unit is matched only with the control units whose propensity score falls in a predefined neighborhood (caliper) of the propensity score of the treated unit. If the neighborhood does not contain control units, some treated units are not matched. If the caliper is too small, many treated observations are discarded, and the results are no longer representative of the population treated. We chose a caliper of 0.001 , which seems to be a good compromise for avoiding bad matches, while still leading to representative results. Instead, in the case of the nearest neighbor and kernel matching methods, all treated observations are matched, but this occurs at the cost of a lower quality of the match (Smith and Todd, 2005; Dehejia and Wahba, 2002).
} 
Table F.1: Distribution of explanatory variables in the original and matched samples

\begin{tabular}{|c|c|c|c|c|}
\hline & \multicolumn{2}{|c|}{$\begin{array}{c}\text { Original sample } \\
(\# \text { obs }=2441)\end{array}$} & \multicolumn{2}{|c|}{$\begin{array}{l}\text { Matched sample } \\
\quad(\# \text { obs = 632) }\end{array}$} \\
\hline & $\begin{array}{l}\text { Difference in } \\
\text { means }\end{array}$ & $\begin{array}{l}\text { Standard } \\
\text { deviation }\end{array}$ & $\begin{array}{l}\text { Difference in } \\
\text { means }\end{array}$ & $\begin{array}{l}\text { Standard } \\
\text { deviation }\end{array}$ \\
\hline Log (ASA age) & 0.00 & 0.85 & 0.00 & 0.84 \\
\hline $\log$ (distance) & 0.36 & 0.96 & 0.20 & 0.95 \\
\hline $\log (\text { distance })^{2}$ & 5.48 & 14.81 & 2.90 & 14.91 \\
\hline Border & 0.02 & 0.30 & -0.03 & 0.28 \\
\hline Colony & -0.01 & 0.26 & 0.01 & 0.26 \\
\hline Language & 0.10 & 0.42 & 0.05 & 0.41 \\
\hline $\log \left(G P_{i}\right)^{*} \log \left(G P_{j}\right)$ & -28.79 & 74.06 & -16.11 & 70.40 \\
\hline $\begin{array}{l}\text { Difference in } \\
\text { temperature }\end{array}$ & 1.75 & 6.78 & 0.98 & 6.61 \\
\hline Log (trade) & -1.07 & 2.29 & -0.74 & 2.15 \\
\hline Face-to-face trade & -0.20 & 0.80 & -0.05 & 0.23 \\
\hline
\end{tabular}

Notes: Difference in means is calculated as the mean in the control group minus the mean in the treatment group. Standard deviation refers to the pooled standard deviation of both the control and treatment group. Radius propensity score matching with a caliper of 0.001 is used.

Table F.2: Addressing endogeneity by propensity score matching

\begin{tabular}{|c|c|c|c|c|}
\hline \multicolumn{5}{|c|}{ Dependent variable: $\log$ (traffic) } \\
\hline & (1) & (2) & (3) & (4) \\
\hline & \multicolumn{2}{|c|}{ Original sample } & \multicolumn{2}{|c|}{ Matched sample } \\
\hline & $\begin{array}{c}\text { Full } \\
\text { sample }\end{array}$ & $\begin{array}{c}\text { Distance } \\
<8000 \mathrm{~km} \\
\end{array}$ & $\begin{array}{c}\text { Full } \\
\text { sample }\end{array}$ & $\begin{array}{c}\text { Distance } \\
<8000 \mathrm{~km} \\
\end{array}$ \\
\hline \multirow{2}{*}{$\begin{array}{l}\text { Dummy equal to } 1 \\
\quad \text { if ALI > } 10 \text { (=median) }\end{array}$} & 0.053 & $0.13 * *$ & $0.16^{* * *}$ & $0.18 * *$ \\
\hline & $(0.34)$ & $(0.04)$ & $(0.00)$ & $(0.018)$ \\
\hline Full set of control variables & Yes & Yes & Yes & Yes \\
\hline Observations & 2,441 & 2,073 & 632 & 506 \\
\hline Adjusted $\mathrm{R}^{2}$ & 0.84 & 0.85 & 0.91 & 0.93 \\
\hline
\end{tabular}




\section{REFERENCES}

Dehejia, Rajeev H. and Sadek Wahba. 2002. "Propensity Score Matching Methods for Non-Experimental Causal Studies." Review of Economics and Statistics, 84(1): 151-161.

Smith, Jeffrey, and Petra Todd. 2005. "Does Matching Overcome Lalonde's Critique of Non Experimental Estimators?" Journal of Econometrics, 125: 305-353. 